the minutes can be supplied with perfect certainty by calculation; but in observations of a transit of Venus the contacts from apparent contact to the "last appearance of any marked "disturbance of the illumination" may, in a moderately bright field, extend over more than a minute of time; and if any misconception of the kind of contact which has been observed should be possible from ambiguity in the description given by the observer, then a serious error may be introduced into the discussion of the results from the adoption of a wrong minute and wrong kind of contact for this observation. In the use of chronometers mistakes of half a minute have occasionally been made by taking the "arrow end" instead of the "longer end" of the seconds hand.

In all cases, therefore, such precautions should be taken to verify the minutes and half-minutes that errors of entry can be asserted to be impossible.

I9. Approximate latitudes and longitudes of the station, and the authorities from which they are derived, should in all cases be given, to gether with the local names of the station.

20. The position of the observer should be permanently marked, and, if possible, referred to three or more surrounding natural objects, as mountains, so that the position can be recovered if the mark should be accidentally destroyed.

21. In cases where the errors of the chronometers or clocks and the geographical position of the observers are independently determined, the observations upon which these determinations rest should be given.

22. The descriptions of the contacts which correspond to the time records should be written out by each observer, and entered in an indelible form, before any discussion or comparison of the observatious with those made by any other observer has been made. On no account is a written figure to be altered. On no account is a new figure to be written upon an old one. Any correction is to be written on another line, and attested by the signature of the observer.

23. Copies of these observations, authenticated by the signature of the observer, with the necessary materials for the determination of clock-errors, longitudes, and latitudes, should be forwarded by the next or following mail to the Committee at the Royal Society, Burlington House, London. In the case of the Government expeditions, the original documents must be placed in the hands of the official in charge of the Treasury chest at the station, by whom the originals will be retained until the Committee have acknowledged the receipt of the copies and forwarded instructions for the despatch of the originals.

24. Practice with the artificial models of the transit will be useful to observers as a preparation for the slowne:s with which changes in the appearances piesented near the internal contacts take place. But the exact phases presented in the real transit cannot at present be reproduced in the models, and, unless care is taken, model practice may do more harm than good in leading observers to expect a definite succession of phenomena near the internal contacts which they may be unable to recognise in the actual transit. The complicated phenomena presented near the internal contacts are, no doubt, chiefly due to diffractional irra. diation; but in the case of the models we have the sun and Venus bounded by hard edges. The diffraction phenomena beyond the geometrical boundary of the artificial sun, and the interference phenomena between the limbs of the sun and Venus, are continually changing as the disc, which represents Venus, approaches nearer and nearer the hard edge which represents the geometrical boundary of the sun's disc. These conditions introduce complications into the phenomena seen with the model which have nothing exactly corresponding to them in the real transit; whilst, on the other hand, the presence of the partial illumination of the atmosphere of Venus introduces difficulties in the observation of the real transit which have nothing exactly corresponding to them in the models in ordinary use.

\section{ATOMIC WEIGHTS 1}

SEVEN years after the publication of the first volume of Dalton's "New System of Chemical Philosophy," and therefore at a time when the data from which atomic weights could be deduced were few and inaccurate, Prout I "The Constants of Nature. Part V. A Recalculation of the Atomic Weights." By Frank Wigglesworth Clarke, S. B., Pr. fessor of Chemistry and Physics in the University of Cincinnati. (Washington: Smithsonian Institution, 1882.) promulgated the hypothesis that the atomic weights of all the elements are multiples of that of hydrogen.

This hypothesis was soon shown to be without foundation in fact, but in the modified form given to it by Dumas--viz. the atomic weights of all the elements are whole, half, or quarter multiples of that of hydrogen-it found very considerable acceptance among chemists, although it was strongly opposed by many.

In I860 Stas published the results of very carefullymade determinations of the atomic weights of nitrogen, chlorine, sulphur, potassium, sodium, lead, and silver. Stas concluded from these results that Prout's hypothesis is purely imaginary; that each elementary substance is a distinct entity, and exhibits no simple mass relations with other elements.

Marignac criticised the numbers obtained by Stas, objecting that unless an atomic weight is determined by wholly different series of experiments it cannot be accepted as final, and making the somewhat astonishing statement that possibly the composition of a given compound is not altogether invariable. The reply of Stas appeared in the form of his famous "Nouvelles recherches sur les lois des proportions chimiques, sur les poids atomiques et leur rapports mutuels," wherein the fixity of composition of many compounds was firmly established, and numbers were deduced, from widely different and most carefully conducted series of experiments, for the atcmic weights of silver, iodine, bromine, chlorine, sulphur, nitrogen, lithium, potassium, sodium, and lead, which numbers appeared finally to negative the hypothesis of Prout, even in the form given to it by Dumas.

The experimental work of Stas has been accepted as unimpeachable by every chemist. The "Nouvelles recherches" is a classical work. But in I878 Dumas showed that pure silver, prepared by the method adopted by Stas, gave up weighable quantities of oxygen when heated in vacuo. The numbers given by Stas as the atomic weights of the elements enumerated above may therefore not represent the true atomic weights of these elements. The importance of the discovery made by Dumas is emphasised when we know that the atomic weight of silver is a fundamental number, on which most of the other atomic weights determined by Stas depend.

In 1872 , Crookes communicated to the Royal Society the results of an extremely careful determination of the atomic weight of thallium; the mean number obtained, $203^{\circ} 642$, was regarded by Crookes as strongly against Prout's hypotbesis.

Recent work, physical as well as chemical, has again caused attention to be turned to the hypothesis which would regard the elements as forms of one kind of matter.

The necessity for a revision of many atomic weights has impressed itself on chemists; and several very carefu revisions, notably that of the atomic weight of antimony by Cooke, and of aluminium by Mallet, have recently been made. But in addition to these new data there exist many determinations, which, if properly collected and digested, would be of much importance. Prof. Clarke has done this most admirable service to science.

"Atomic Weight Determinations; a Digest of Inves. tigations published since 1814, " by Prof. G. T. Becker, has already appeared as Part iv. of the Smithsonian Constants of Nature; Prof. Clarke's Recalculation completes the Digest; together these form a contribution to chemical science of the first importance.

The ratio between the atomic weights of oxygen and hydrogen is that first discussed. Each series of experiments is considered separately ; the mean value is found and the probable error of this mean is assigned by the method of least squares. Those elements, the atomic weights of which have been most carefully determined, viz. silver, chlorine, bromine, iodine, potassium, sodium, and sulphur, are next considered.

The discussion of atomic weights involves many chemi- 
cal considerations: more or less weight must be given to different results on other than purely mathematical grounds; hence identical final results would not always be arrived at by different calculators starting from the same experimental data. Inasmuch as "the atomic weight of each element involves the probable error of all the other elements to which it is directly or indirectly referred," it may happen that the probable error attaching to an atomic weight determination is large, although the experimental data are extremely accurate. Thus, Crookes, by very accurate experiments, found the atomic weight of thallium to be 203.642 ; but this number supposes that $\mathrm{NO}_{3}=6 \mathrm{I} .889$; the value to be now assigned to the atomic weight of thallium depends on the accuracy with which the atomic weights of oxygen and nitrogen have been determined. The work of Crookes simply fixes, with great accuracy, the ratio between the equivalents of $\mathrm{Tl}$ and $\mathrm{NO}_{3}$.

The most probable value for the atomic weight of oxygen is found to be $15^{\circ} 9633(\mathrm{H}=\mathrm{I})$, with a probable error of $\pm{ }^{\circ} 0035$; any error which there may be in this determination is involved in the determinations of the atomic weights of most of those elements which come after oxygen. When the atomic weight is large, the error thus introduced may be considerable : thus if $\mathrm{O}=15^{\circ} 9633$ $\mathrm{Ur}=238^{\circ} 482$, but if $\mathrm{O}=16^{\circ} \mathrm{Oo} \mathrm{Ur}=239^{\circ} \mathrm{O} 3$; difference $=0.548$.

Some of the weighings involved in the calculations have been reduced to absolute standards, others are only uncorrected weighings in air ; hence an error is sometimes introduced which cannot be eliminated.

The discovery of Dumas that silver prepared by the method of Stas, occludes weighable quantities of oxygen, has been already referred to ; in four experiments Dumas found that I kilogram of silver occluded $82,226,140$, and 249 milligrams of oxygen respectively; the largest of these numbers is taken by Prof. Clarke as "Dumas' correction." The effect of applying this correction is generally very slightly to lower the value of the atomic weight; the following table exhibits this effect in a few instances :-

\begin{tabular}{|c|c|c|c|c|c|c|}
\hline & & Uncorrected. & & Corrected. & & . \\
\hline Sils & $\ldots$ & 107.923 & $\cdots$ & $107 \cdot 896$ & $\cdots$ & -.02 \\
\hline ine & $\ldots$ & $35^{\circ} 45^{\prime}$ & $\ldots$ & $35^{\circ} 47^{8}$ & $\ldots$ & +027 \\
\hline Bro & $\ldots$ & 79.751 & $\ldots$ & 79 & $\ldots$ & +.027 \\
\hline$\ldots$ & $\ldots$ & I26.848 & .. & 126 & & +027 \\
\hline ot & $\cdots$ & $39^{\circ} 109$ & $\cdots$ & 39 & & - 026 \\
\hline odium & $\ldots$ & $23^{\circ} 05^{I}$ & $\ldots$ & $23^{\circ} \mathrm{O} 24$ & $\ldots$ & -.027 \\
\hline
\end{tabular}

In the appendix is given a table containing the mean atomic weights (with probable errors attiched) for all the elements, calculated from the most trustworthy data. It is shown that twenty-five out of the sixty-six elements considered have atomic weights the values of which differ by less than one-tenth of a unit from whole numbers, $(\mathrm{H}=\mathrm{I}$ ) but many of those numbers which differ by more than this fraction involve any error which there may be in the determination of the value of the atomic weight of oxygen, multiplied many times. If the possible error in the value for oxygen be transferred to that for hydrogen, i.e. of $\mathrm{O}=16$, then it is shown that forty-four out of the sixty-six elements have atomic weights differing by less than one-tenth of a unit from whole numbers. Of these forty-four elements, twenty-six show plus, and thirteen minus variations from whole numbers. Those which exhibit minus variations are discussed in detail; the values for the atomic weights of seven of these have not been determined with any great accuracy; silver alone has a value which carries "very much weight against the hypothesis of Prout." Cf those elements, twenty-six in number, the atomic weigirts of which exhibit plus variations (less than $O^{\prime} I$ ) from whole numbers, three-viz. $\mathrm{Nb}, \mathrm{Yt}$, and $\mathrm{Ur}$--have values which have been very inaccurately determined; seven involve "Dumas' correction," the application of which will bring the values nearer whole numbers ( $\mathrm{Al}, \mathrm{As}, \mathrm{Ba}, \mathrm{Cd}, \mathrm{Li}, \mathrm{P}$, and $\mathrm{Na}$ ). Special sources of possible error are indicated in the discussion of the atomic weights of $\mathrm{Al}, \mathrm{Ca}, \mathrm{F}$. Five, of the twenty-six elements, have atomic weights the values of which involve errors due to the possible occlusion of hydrogen by the metals when reduced from their compounds ( $\mathrm{Co}, \mathrm{Fe}, \mathrm{Ir}, \mathrm{Ni}$, and $\mathrm{W})$. In many other cases the variations from whole numbers are extremely small, i.e. much less than one-tenth of a unit. "In short in the majority of instances the errors may be diminished by corrections which are in all probability needed, and which we can easily point out."

Twenty-six elements have atomic weights the values of which vary more than one-tenth of a unit from whole numbers; of these twenty-six, three-viz. $\mathrm{Cl}, \mathrm{Rb}$, and $\mathrm{Sr}$ have values nearly half multiples of that of hydrogen; the atomic weights of nine-viz. $\mathrm{Sr}, \mathrm{Au}, \mathrm{In}, \mathrm{La}, \mathrm{Rh}, \mathrm{Ru}$, $\mathrm{Si}, \mathrm{Te}$, and $\mathrm{Zr}-$ have been very imperfectly determined; the atomic weights of $\mathrm{Sb}, \mathrm{Ce}, \mathrm{Be}, \mathrm{Yt}, \mathrm{Pt}$, and $\mathrm{Hg}$ are discussed, and it is shown that the atomic weights of these elements may come within Prout's hypothesis; no criticism is offered on the atomic weights of $\mathrm{Cr}(52 \cdot 129 \pm$

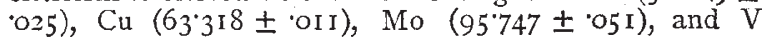
$(51 \cdot 373 \pm \cdot 024)$.

The value to be assigned to iodine (126:848 \pm 022) depends on that for silver; at present iodine stands as an important exception to Prout's rule. Potassium presents a serious objection ; but if "Dumas' correction" is applied $\mathrm{K}$ becomes $39^{\circ} \mathrm{O} 83[\mathrm{O}=\mathrm{r} 6]$. Clarke concludes by saying that although he began his examination of atomic weights strongly prejudiced against Prout's hypothesis, the facts have obliged him to give it "a very respectful consideration." "All chemists must at least admit that the strife over it is not yet ended, and that its opponents cannot thus far claim a perfect victory."

The recalculation of atomic weights shows clearly to the chemist what experimental work ought now to be undertaken; revisions of the atomic weights of tellurium, silicon, boron, mercury, chromium, manganese, uranium, and gold are urgently called for. The "periodic law" requires that the atomic weight of tellurium should be smaller than that of iodine; although the mean number recently obtained by Wills is greater than 127 , yet this number cannot be accepted as final. Several results brought out by Clarke have an important bearing on the "periodic law." In most of the tables of elements arranged in accordance with the law, didymium is placed before cerium and lanthanum; Clarke however shows that $\mathrm{Di}=144.573( \pm .03 \mathrm{I}) ; \mathrm{Ce}=140^{\circ} 424\left( \pm{ }^{\circ} \mathrm{OI} 7\right)$; and $\mathrm{La}=138.526( \pm .03)$. Brauner, in his paper recently published in Chem. Soc. Journal, finds Di $=146.18$ (mean of three results), and $\mathrm{La}=139.58$ (mean of two results). We may therefore conclude that $\mathrm{La}<\mathrm{Ce}<\mathrm{Di}$. These elements then come in series 8 ; lanthanum in group III. giving the characteristic oxide $\mathrm{La}_{2} \mathrm{O}_{3}$, cerium in group IV. giving the oxide $\mathrm{Ce}_{2} \mathrm{O}_{4}$, and didymium in group $\mathrm{V}$. with the oxide $\mathrm{Di}_{2} \mathrm{O}_{5}$, which oxide has been lately prepared and examined by Brauner (Chem. Soc. Jnl. Trans., 1882, p. 68).

Prof. Clarke's work may be taken as a type of what is now so much wanted in chemistry : a careful collection and digestion of masses of facts. We seem to be forgetting that chemistry is a science, not a collection of facts. Every week adds fresh material to the heap; the science is in danger of being crushed beneath the load of details.

M. M. PATtison MUIR

\section{FIRE RISKS FROM ELECTRIC LIGHTING}

$A$ VERY strong and influential committee was recently A formed by the Society of Electricians to draw up a series of rules and regulations not only for the guidance and instruction of those who have electric lighting apparatus installed on their premises, but for the reduction to 